\title{
DSP based Controller with Switching Loss Reduction Technique for Brushless DC Motor Drive System
}

\author{
K. Premalatha, D. Rajalakshmi, R. Kavitha
}

\begin{abstract}
PMBLDC motor finds its application in various fields which includes hybrid electric vehicles, robotic applications with high precision control, fans and industries. This paper presents DSP based control with switching loss reduction technique for Permanent Magnet Brushless DC motor. Firing pulses for power switches are generated using DSP TMS320C2407 based on hall sensor feed-back. The algorithm is written in $C$ using code composer studio to generate single mode $P W M$ pulses and multiple PWM pulses. To reduce the switching losses three switches are turn on and turn off with single pulse and the remaining three switches are with multiple PWM pulses. The hardware is implemented and the trapezoidal stator voltage and corresponding gating signals are measured for various speed. The experimental results validate the performance of proposed system.
\end{abstract}

Keywords-PMBLDC, DSP controller, Trapezoidal PWM

\section{INTRODUCTION}

Permanent Magnet Brushless DC Motor (PMBLDC) is used in wide range of speed and torque control applications[1]. Permanent magnet motors like Permanent Magnet synchronous motor and PMBLDC motors are becoming more prominent now a days in electric vehicle as it has higher power density ,efficiency and linear torquespeed characteristics[2]. Technological advancements in power electronic converters leads to efficient and precise control of PMBLDC motor. PMBLDC motor utilize permanent magnets for its excitation and rotor position Hall sensors are needed to perform electrical commutation[3]. DSP controller TMS320C240 have inbuilt microcontroller with peripherals essential for motor control applications[4]. The brushless dc motor with inverter operating in $120^{\circ}$ mode is analyzed in this paper. The advantage of $120^{\circ}$ mode of operation is larger tolerance which prevents inverter malfunction which occurs due to shoot through fault[5]. Novel inverter topology is proposed for brushless dc motor drive system with a high performance and reduced cost[6-7]. High performance digital controller for brushless dc motor using dedicated controller MC33035 and MC33039 and a prototype model is constructed and tested [8-9]. In this paper, PMBLDC motor drive system is implemented using DSP controller and its performance is analyzed. Three semiconductor switching devices are controlled by multiple PWM and the remaining three switches are controlled with single pulse so as to reduce the switching losses.

\section{PMBLDC DRIVE SYSTEM CONFIGURATION}

The proposed system consists of PMBLDC motor, three phase inverter and DSP controller TMS320C240 as illustrated in fig. 1. The PMBLDC motor is equipped with three Hall effect sensors that are placed 120 degrees apart. The Hall sensor senses the rotor position to indicate which of the three phases of the motor is to be excited. The DSP control algorithm is written and the output of the controller is a sequence of gating signals pulse width modulated to drive the inverter.

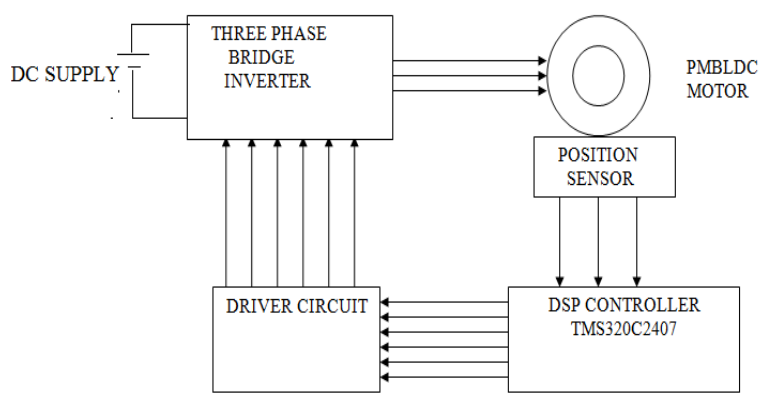

Fig.1 PMBLDC motor drive system configuration

\section{HARDWARE IMPLEMENTATION}

The PMBLDC drive system consists of power circuit, control hardware and software. The Power circuit comprises of MOSFET IRFP450 based inverter and its associated opto-coupler, driver circuit. The control circuit consists of the power supplies, isolators and the rotor speed and position sensing circuits. Programming is performed in DSP TMS320C2407 to generate firing pulses to the inverter.

The hall effect sensor feedback from the PMBLDC motor is fed as input to the port A of the DSP processor. The TMS320C2407 processor generates the pulses required

Revised Manuscript Received on 14 August, 2019.

K.Premalatha, Associate Professor, Department of Electrical and Electronics Engineering,Kumaraguru College of Technology, Coimbatore, Tamilnadu, India(Email: premalatha.k.eee@kct.ac.in)

D.Rajalakshmi, Associate Professor, Department of Electrical and Electronics Engineering,Kumaraguru College of Technology, Coimbatore, Tamilnadu, India(Email: rajalakshmi.d.eee@kct.ac.in)

R.Kavitha, Associate Professor, Department of Electrical and Electronics Engineering,Kumaraguru College of Technology, Coimbatore, Tamilnadu, India.(Email: kavitha.r.eee@kct.ac.in) 


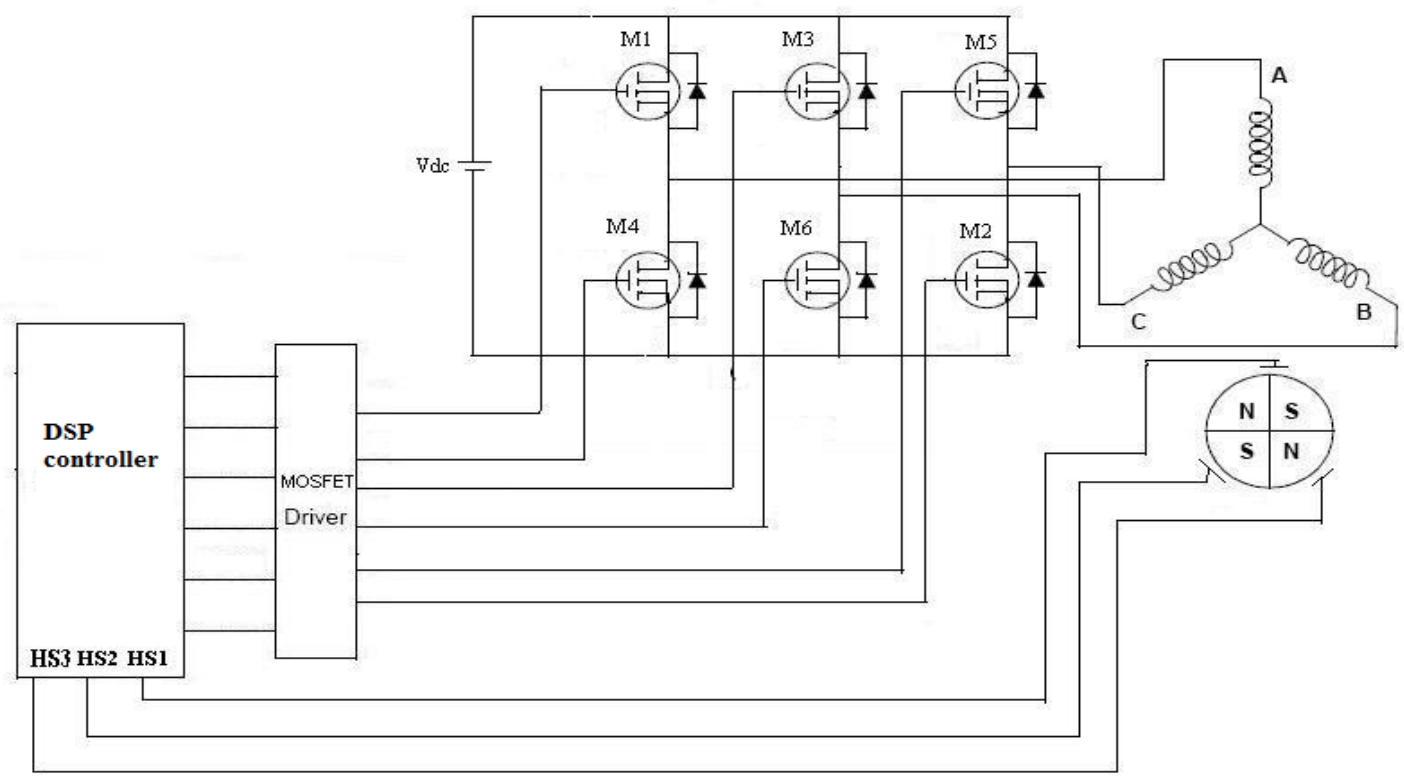

Fig. 2 PMBLDC Drive System using DSP MS320C2407

to drive the MOSFET. Isolation from the power circuit is provided using opto-coupler TLP250 and pulses are amplified using driver IC IR2110 and inverter output is fed to stator. Three phase bridge inverter fabricated using nchannel MOSFET is operated in 120 degree mode to provide square wave current excitation to the stator windings and is shown in fig.2. The MOSFET used is IRFP450 with ratings of $500 \mathrm{~V}, 14 \mathrm{~A}$. A RCD snubber circuit is used for overvoltage protection. Overcurrent protection is provided by giving $5 \mathrm{v}$ to the shut down pin of IR2110. The output pulses from the DSP are coupled using a noninverting hex buffer CD4050 to boost up the current. The switching states for for clockwise rotation in 120 degree mode is given in table. 1 .

Table 1 Switching states for clockwise rotation in 120 degree mode

\begin{tabular}{|l|l|l|l|l|l|l|l|l|l|}
\hline STATE & \multicolumn{3}{|c|}{ HALL } & \multicolumn{7}{c|}{ SWITCHING DEVICE } \\
& SENSORS & \multicolumn{7}{l|}{} \\
\hline & H3 & H2 & H1 & 6 & 5 & 4 & 3 & 2 & 1 \\
\hline 1 & 1 & 0 & 0 & 1 & 0 & 0 & 0 & 0 & 1 \\
\hline 2 & 1 & 0 & 1 & 1 & 1 & 0 & 0 & 0 & 0 \\
\hline 3 & 0 & 0 & 1 & 0 & 1 & 1 & 0 & 0 & 0 \\
\hline 4 & 0 & 1 & 1 & 0 & 0 & 1 & 1 & 0 & 0 \\
\hline 5 & 0 & 1 & 0 & 0 & 0 & 0 & 1 & 1 & 0 \\
\hline 6 & 1 & 1 & 0 & 0 & 0 & 0 & 0 & 1 & 1 \\
\hline
\end{tabular}

Specification of PMBLDC motor drive system

Power

$-1 / 2 \mathrm{hp}$

Stator voltage

Speed

- 140V (line to line)

Poles

- $1500 \mathrm{rpm}$

- 4 made of $\mathrm{NdFeB}$

Hall position sensors

- 3 nos placed 120 degrees apart

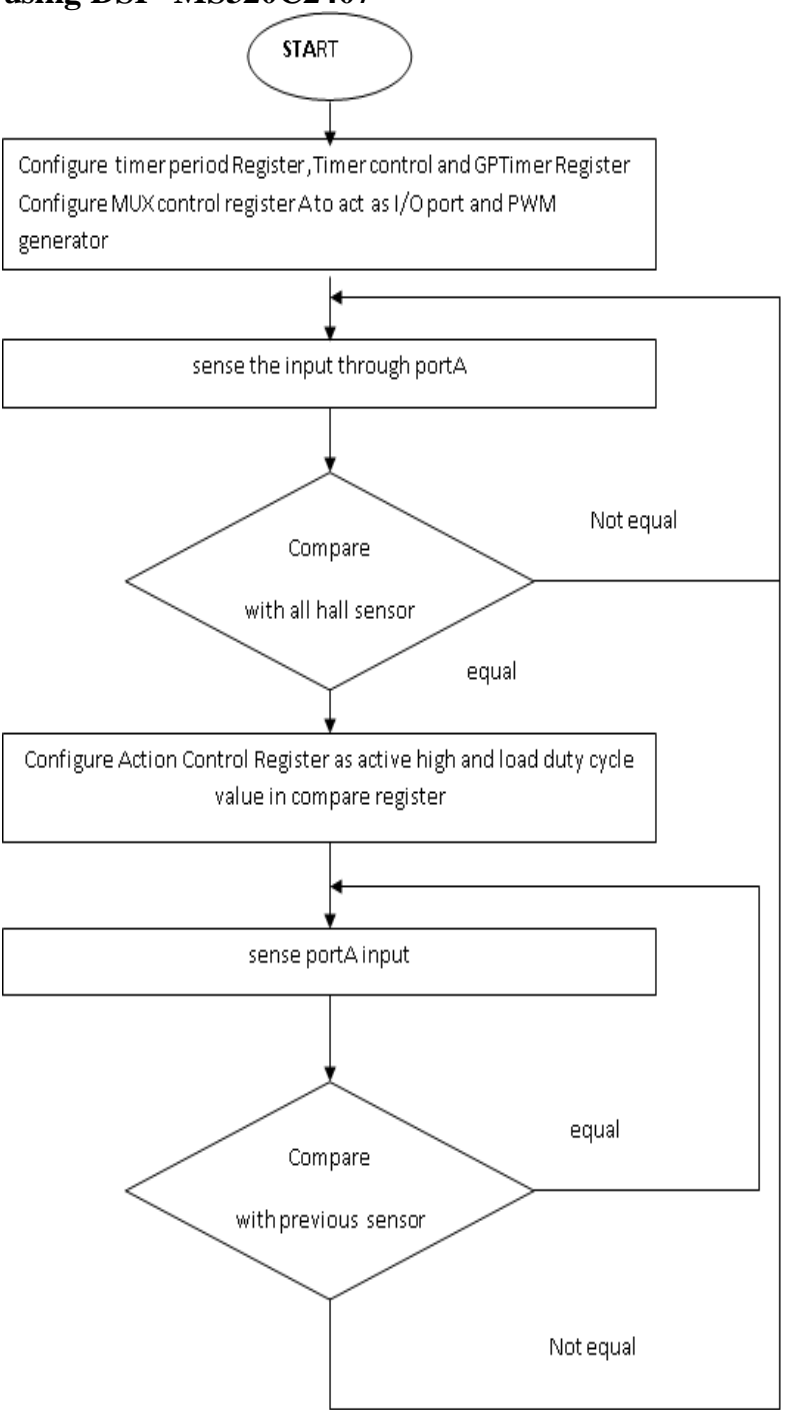

Fig. 3. Algorithm for generating pulses 
The software profile developed for single pulse on modeand multiple pulse PWM mode and the algorithm is shown in fig.3. In PWM mode, action control register is configured in active high mode and the total period is loaded in period register and on time is loaded in compare register. The speed variation is obtained by varying the pulse width.

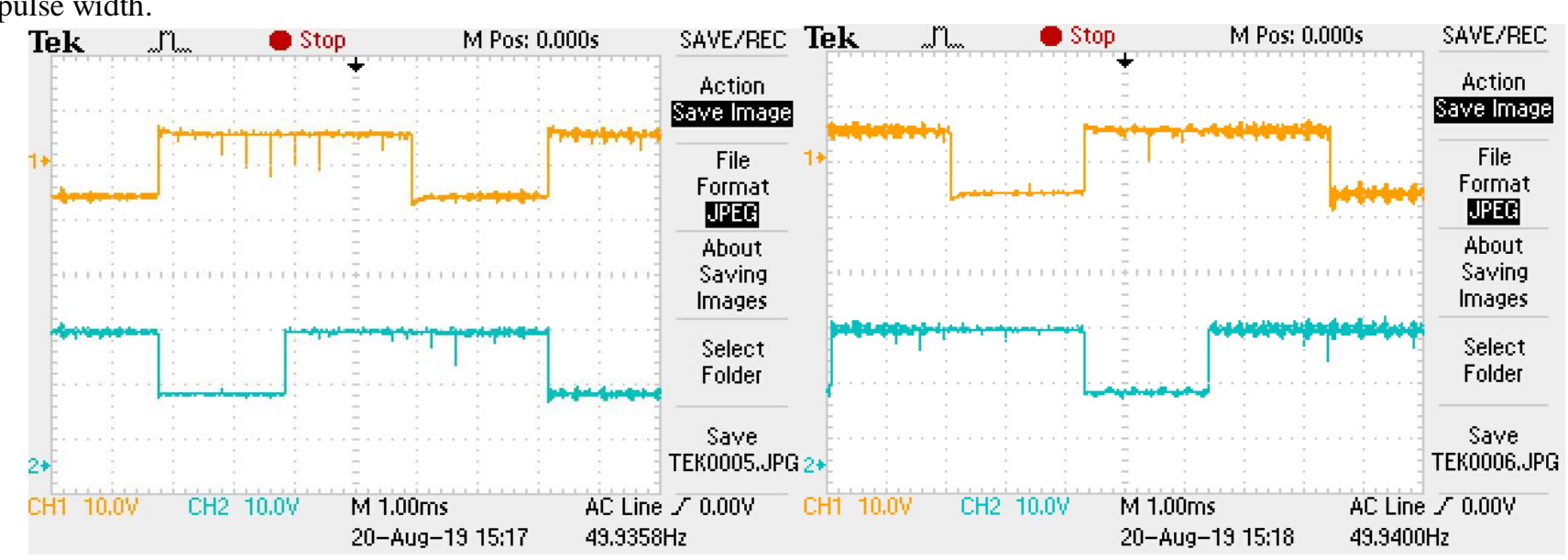

(a)

Fig. 4 Single pulse : (a) 1,3 (b) 1,5

\section{RESULTS}

A VSI inverter has been implemented in hardware and the Stator Voltage - Line to Line and PWM gating pulses are measured. The upper positive group switches are 1, 3, 5 controlled using PWM pulses and the lower negative group (b)

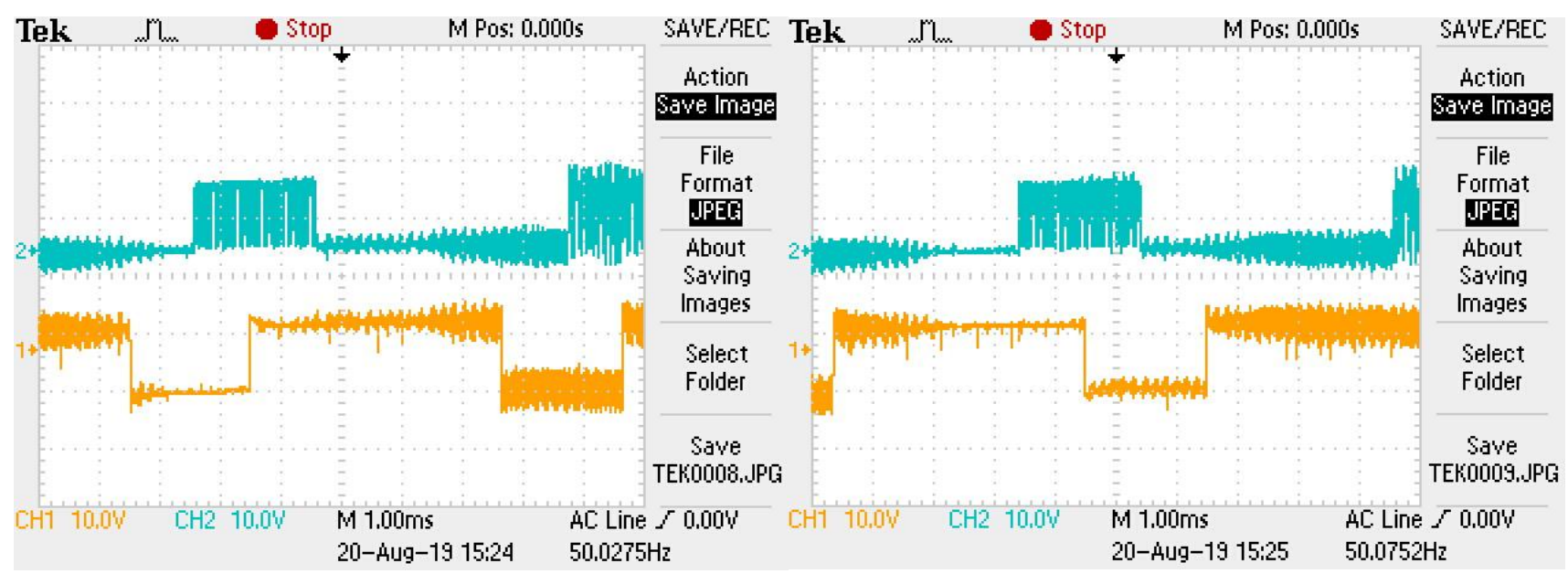

(a)

Fig. 5 PWM pulse : (a) 1,2 (b) 1,6

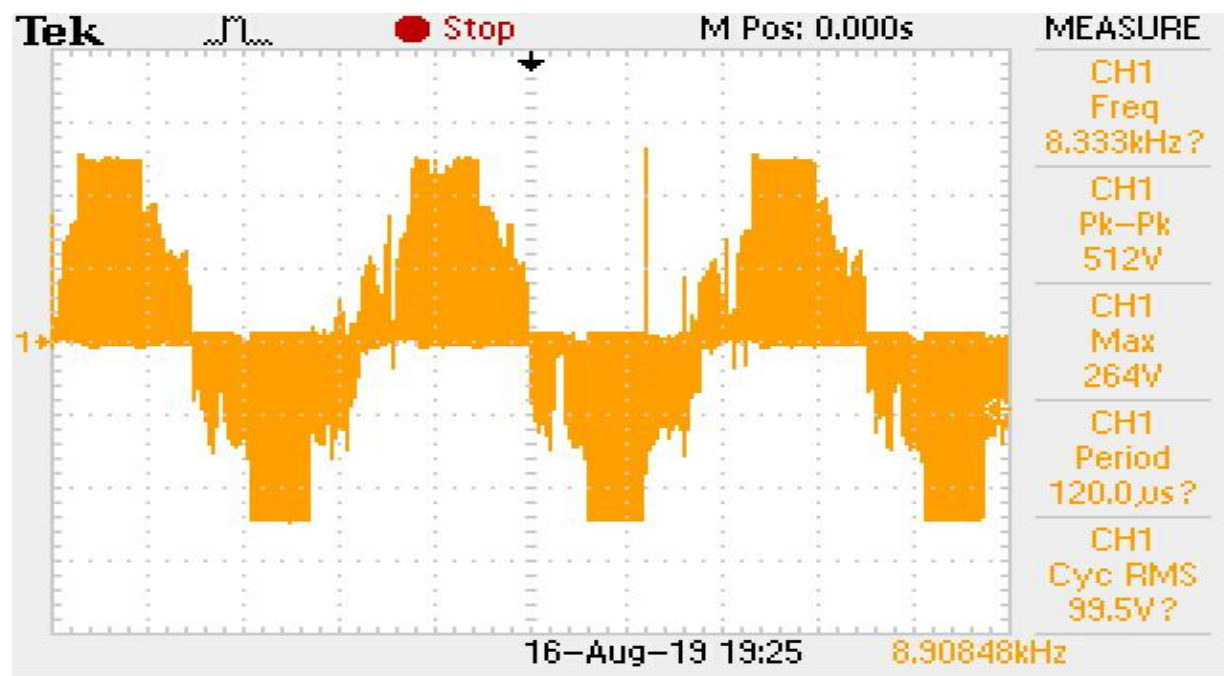

Fig.6. Stator Voltage - Line to Line voltage for speed $900 \mathrm{rpm}$ 


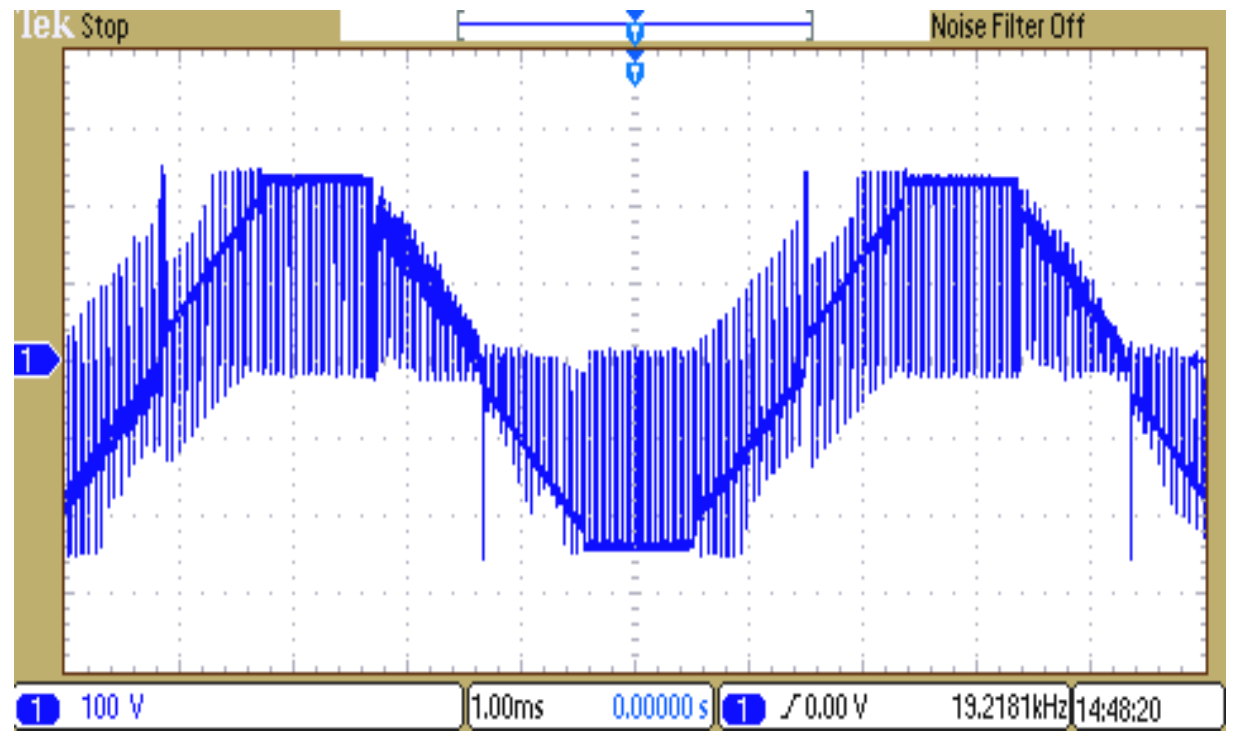

Fig. 7 Stator Voltage - Line to Line voltage for speed $540 \mathrm{rpm}$

switches 4,6,2 are controlled by single pulse mode. The waveforms of Fig.4 (a)-(b) corresponds to the single pulse mode. The waveforms of Fig.5 (a)-(b) corresponds to the PWM mode.

\section{CONCLUSION}

The proposed DSP based control offers reduction in switching losses and has been implemented in hardware. The algorithms are developed in DSP for single pulse mode and multiple pulse PWM mode and have been tested with MOSFET based inverter circuit. The stator voltage and PWM pulses are measured for various speed and the performance of the PMBLDC motor drive is analyzed. The combination of single pulse mode and multiple PWM mode has resulted in reduction switching losses. In future.Sensorless techniques can be implemented as the hall position sensors are expensive and fragile components in the drive system.

\section{REFERENCES}

1 Park, J. S., Lee, K. D., Lee, S. G., \& Kim, W. H. (2018). Unbalanced ZCP Compensation Method for Position Sensorless BLDC Motor. IEEE Transactions on Power Electronics, 34(4), pp.3020-3024.

2 Sandeep, V., \&Shastri, S. (2019). Analysis and Design of PMBLDC Motor for Three Wheeler Electric Vehicle Application. In E3S Web of Conferences (Vol. 87, p. 01022). EDP Sciences.

3 Cheng, K. Y., \&Tzou, Y. Y. (2003). Design of a sensorless commutation IC for BLDC motors. IEEE Transactions on Power Electronics, 18(6), 1365-1375.

4 Chern, T. L., Chang, J., \& Chang, G. K. (1997). DSPbased integral variable structure model following control for brushless DC motor drivers. IEEE Transactions on Power Electronics, 12(1), 53-63.

5 Sudhoff, S. D., \& Krause, P. C. (1990). Operating modes of the brushless DC motor with a 120 degrees inverter. IEEE Transactions on Energy Conversion, 5(3), 558564.

6 Xu, Y., Wei, Y., Wang, B., \&Zou, J. (2015). A novel inverter topology for brushless DC motor drive to shorten

commutation time. IEEE Transactions on Industrial Electronics, 63(2), 796-807.

7 Kavitha, R., \&Thottungal, R. (2018). Reconfigurable Selective Harmonic Elimination Technique for Wide

Range Operations in Asymmetric Cascaded Multilevel Inverter. Journal of Power Electronics, 18(4), 10371050.

8 Rodriguez, F., \&Emadi, A. (2007). A novel digital control technique for brushless DC motor drives. IEEE transactions on industrial electronics, 54(5), 2365-2373.

9 Sathyan, A., Milivojevic, N., Lee, Y. J., Krishnamurthy, M., \&Emadi,A. (2009). An FPGA-based novel digital PWM control scheme for BLDCmotor drives. IEEE transactions on Industrial Electronics, 56(8), 3040-3049. 